\title{
Upregulation of microRNA-25 associates with prognosis in hepatocellular carcinoma
}

\author{
Zhong-xue Su*, Juan Zhao' ${ }^{1 *}$ Zhong-hou Rong ${ }^{1}$, Wen-mao Geng ${ }^{1}$, Ya-guang Wu and Cheng-kun Qin ${ }^{1}$
}

\begin{abstract}
Background: Accumulating evidence has shown that up-regulation of microRNA-25(miR-25) is associated with the prognosis of several types of human malignant solid tumors. However, whether miR-25 expression has influence on the prognosis of hepatocellular carcinoma (HCC) is still unknown.

Methods: The differentially expressed amount of the miR-25 was validated in triplicate by quantitative reverse-transcription polymerase chain reaction (qRT-PCR). Survival rate was analyzed by log-rank test, and survival curves were plotted according to Kaplan-Meier. Multivariate analysis of the prognostic factors was performed with Cox regression model.
\end{abstract}

Results: The expression of miR-25 was significantly upregulated in HCC tissues when compared with adjacent normal tissues $(p<0.0001)$. Patients who had high miR-25 expression had a shorter overall survival than patients who had low miR-25 expression (median overall survival, 31.0 months versus 42.9 months, $p=0.0192$ ). The multivariate Cox regression analysis indicated that miR-25 expression ( $H R=2.179 ; p=0.001)$, TNM stage ( $H R=1.782$; $p=0.014)$, and vein invasion ( $H R=1.624 ; p=0.020)$ were independent prognostic factors for overall survival.

Conclusion: Our data suggests that the overexpression of miR-25 in HCC tissues is of predictive value on poor prognosis.

Virtual slide: The virtual slide(s) for this article can be found here: http://www.diagnosticpathology.diagnomx. eu/vs/1989618421114309

\section{Introduction}

Hepatocellular carcinoma (HCC) is one of the most malignant solid tumors and is the second leading cause of cancer-related mortality [1]. The established risk factors of $\mathrm{HCC}$ are viral hepatitis, alcohol abuse, and non-alcoholic fatty liver disease [2]. HCC is often diagnosed at an advanced stage, and it is not amenable to standard chemotherapy and is resistant to radiotherapy. In most cases, surgical resection and liver transplantation remain the only curative treatment options. Frequent tumor metastasis and recurrence after surgical intervention lead to the dismal outcome of patients with HCC. The 5-year survival rate of patients with $\mathrm{HCC}$ is approximately $5 \%$, and over 650,000 people die of HCC each year worldwide [3]. The prediction of the prognosis and accurate patient stratification are

\footnotetext{
* Correspondence: dr_suzhongxue@126.com

'Department of Hepatobiliary Surgery, ShanDong Provincial Hospital affiliated to ShanDong University, 324 JingWu Road, Jinan, ShanDong Province 250021, China

Full list of author information is available at the end of the article
}

crucial to optimize personalised treatment. This is currently performed by several staging scores, including the Barcelona Clinic Liver Cancer (BCLC) stage and the Cancer of the Liver Italian Program (CLIP) score [4,5]. Modifications of these staging systems by the addition of new biomarkers, in particular those better reflecting tumor aggressiveness, are likely to improve the prognostic assessment of HCC patients and could therefore fulfill a clinical need. Researchers have found some new prognostic markers of HCC, such as squamous cellular carcinoma antigen, SOX9, and L1 cell adhesion molecule [6-9].

The microRNAs (miRNAs) are a class of highly conserved short noncoding RNAs, which suppress protein expression by inhibiting translation or inducing mRNA degradation by binding to the 3'UTR of target mRNAs $[10,11]$. Beyond the involvement in diverse biological processes, it has been well demonstrated that deregulation or dysfunction of miRNAs can contribute to cancer development $[12,13]$. 
MiR-25 is a member of the miR-106b 25 cluster, which includes miR-106b, miR-93 and miR-25, that is located within intron 13 of the minichromosome maintenance protein 7(MCM7) gene on chromosome 7q22.1 [14,15]. Accumulating evidence has shown that up-regulation of miR-25 is associated with the prognosis of several human malignant solid tumors, including those of the stomach, ovary and prostate [16-18].

Recently, Li Y et al. found that the miR-106b 25 cluster was overexpressed in HCC tissues as well as cell lines, suggesting an important role of miR-106b 25 cluster in carcinogenesis and development of HCC [19]. However, the clinical relevance of miR-25 has not been studied yet, and whether miR-25 expression has influence on the prognosis of HCC is still unknown. Therefore, in the present study, we investigated the feasibility of miR-25 as a novel prognostic biomarker for HCC.

\section{Materials and methods}

\section{Patients and Tissue Specimens}

A total of 131 fresh specimens of HCC and paracarcinomatous liver tissues were obtained from 131 patients who underwent hepatic resection at Provincial Hospital affiliated to ShanDong University between June 2006 and July 2012. Among all the subjects, the mean follow-up period was 47 months (from 11 months to 65 months), and there was no censored case. All these tissues were immediately stored in liquid nitrogen and kept freshly frozen at $-80^{\circ} \mathrm{C}$. Written informed consent was accomplished from the patients for publication of this study and any accompanying images. Study protocol was approved by the Ethics Committee of Provincial Hospital affiliated to ShanDong University. Before surgical therapy, none of the patients had received neoadjuvant chemotherapy, radiation therapy, or immunotherapy. Related important clinical information, including age, gender, serum level of $\alpha$-fetoprotein (AFP), liver cirrhosis, Hepatitis B virus infection, tumor diameter, number of tumor nodules, and TNM stage were collected from each patient's medical records. Clinical staging was performed according to the 2002 American Joint Committee on Cancer/ International Union Against Cancer TNM staging system [20]. Patient characteristics were shown in Table 1.

\section{RNA isolation and quantitative RT-PCR of miRNA-25}

Total RNA was isolated from frozen specimen by homogenizing tissue in Trizol reagent (Invitrogen, Carlsbad, CA, USA), according to the manufacturer's instructions. The purity and concentration of RNA were determined using NanoDrop 1000 spectrophotometer (Thermo Scientific, Wilmington, DE, USA). The differentially expressed amount of the miR-25 was validated in triplicate by quantitative reverse-transcription polymerase chain reaction (qRT-PCR). Briefly, 2 ug of RNA was
Table 1 Relationship between miR-25 expression level and clinicopathologic parameters of hepatocellular carcinoma

\begin{tabular}{|c|c|c|c|}
\hline Factor & No. & miR-25 expression & $P$ value \\
\hline \multicolumn{4}{|l|}{ Gender } \\
\hline Male & 81 & $8.34 \pm 4.85$ & \\
\hline Female & 50 & $8.11 \pm 4.63$ & 0.62 \\
\hline \multicolumn{4}{|c|}{ Age at diagnosis(year) } \\
\hline$\leq 50$ & 53 & $8.01 \pm 5.11$ & \\
\hline$>50$ & 78 & $8.49 \pm 3.89$ & 0.21 \\
\hline \multicolumn{4}{|c|}{ Tumor size(cm) } \\
\hline$\leq 5$ & 62 & $7.99 \pm 5.13$ & \\
\hline$>5$ & 69 & $9.01 \pm 3.79$ & 0.13 \\
\hline \multicolumn{4}{|c|}{ Tumor number } \\
\hline Solitary & 70 & $8.13 \pm 4.34$ & \\
\hline Multiple & 61 & $8.57 \pm 4.89$ & 0.51 \\
\hline \multicolumn{4}{|l|}{ TNM stage } \\
\hline$|-| \mid$ & 72 & $6.34 \pm 3.12$ & \\
\hline III-IV & 59 & $11.01 \pm 5.61$ & 0.01 \\
\hline \multicolumn{4}{|l|}{ Vein invasion } \\
\hline Presence & 79 & $9.12 \pm 4.89$ & \\
\hline Absence & 52 & $7.31 \pm 4.19$ & 0.24 \\
\hline \multicolumn{4}{|l|}{ Cirrhosis } \\
\hline Negative & 44 & $7.12 \pm 3.19$ & \\
\hline Positive & 87 & $8.89 \pm 5.38$ & 0.17 \\
\hline \multicolumn{4}{|c|}{ Hepatitis B virus infection } \\
\hline Negative & 42 & $6.17 \pm 4.65$ & \\
\hline Positive & 89 & $9.21 \pm 4.13$ & 0.09 \\
\hline \multicolumn{4}{|c|}{ Serum AFP level (ng/ml) } \\
\hline$\leq 25$ & 54 & $6.02 \pm 3.87$ & \\
\hline$>25$ & 77 & $10.99 \pm 5.44$ & 0.02 \\
\hline
\end{tabular}

AFP,a-fetoprotein.

added to RT reaction, and then, the cDNA served as the template for amplification of PCR with sequence-specific primers (Sangon Biotech, Shanghai, China) using SYBR PrimeScript miRNA RT-PCR kit (Takara Biotechnology Co. Ltd, Dalian, China) on the 7500 Real-Time PCR systems (Applied Biosystems, Carlsbad, CA, USA). The PCR cycling profile was denatured at $95^{\circ} \mathrm{C}$ for $30 \mathrm{~s}$, followed by 40 cycles of annealing at $95^{\circ} \mathrm{C}$ for $5 \mathrm{~s}$, and extension at $60^{\circ} \mathrm{C}$ for $34 \mathrm{~s}$. Small nucleolar RNA U6 was used as an internal standard for normalization. The cycle threshold $\left(C_{\mathrm{T}}\right)$ value was calculated. The $2^{-\Delta \mathrm{CT}}\left(\Delta \mathrm{C}_{\mathrm{T}}=\mathrm{C}_{\mathrm{TmiR} 25^{-}} \mathrm{C}_{\mathrm{TU} 6 \mathrm{RNA}}\right)$ method was used to quantify relative amount of miR-25.

\section{Statistical analysis}

Statistical analyses were performed using SPSS 13.0 software (Chicago, Ill., USA) and GraphPad Prism 5 (GraphPad 
Software Inc., CA, USA). The comparison of the expression level of miR-25 between HCC tissues and adjacent normal tissues was performed using the two-sample Student's $t$ test. The correlation between the expression level of miR-25 and clinicopathological characters was assessed with the two-sample Student's t test. Survival rate was analyzed by log-rank test, and survival curves were plotted according to Kaplan-Meier. Multivariate analysis of the prognostic factors was performed with Cox regression model. All tests were two tailed and results with $\mathrm{P}<0.05$ were considered statistically significant.

\section{Results}

The expression level of miR-25 in HCC samples and its relationship with clinicopathological characteristics

The expression of miR-25 was significantly upregulated in HCC tissues (mean relative expression level: 8.287, $\mathrm{SD}=4.711$ ) when compared with adjacent normal tissues (mean relative expression level: 4.177, $\mathrm{SD}=2.386, \mathrm{P}<0.0001$, Figure 1). The relationship between miR-25 expression level with clinicopathological variables of $\mathrm{HCC}$ patients was shown in Table 1 . The relative miR-25 expression levels were significantly positively correlated with serum AFP $(\mathrm{p}=0.02)$ and TNM stage $(\mathrm{p}=0.01)$.

However, there was no significantly correlation of miR25 expression with other clinical features such as gender $(\mathrm{p}=0.62)$, age $(\mathrm{p}=0.21)$, liver cirrhosis $(\mathrm{p}=0.17)$, Hepatitis $\mathrm{B}$ virus infection ( $p=0.09)$, vein invasion $(\mathrm{p}=0.24)$, tumor diameter $(\mathrm{p}=0.13)$, or number of tumor nodules $(\mathrm{p}=0.51)$.

The expression levels of miR-25 correlate with prognosis of patients with $\mathrm{HCC}$

Considering that the level of miR-25 expression was significantly correlated with TNM stage and serum AFP

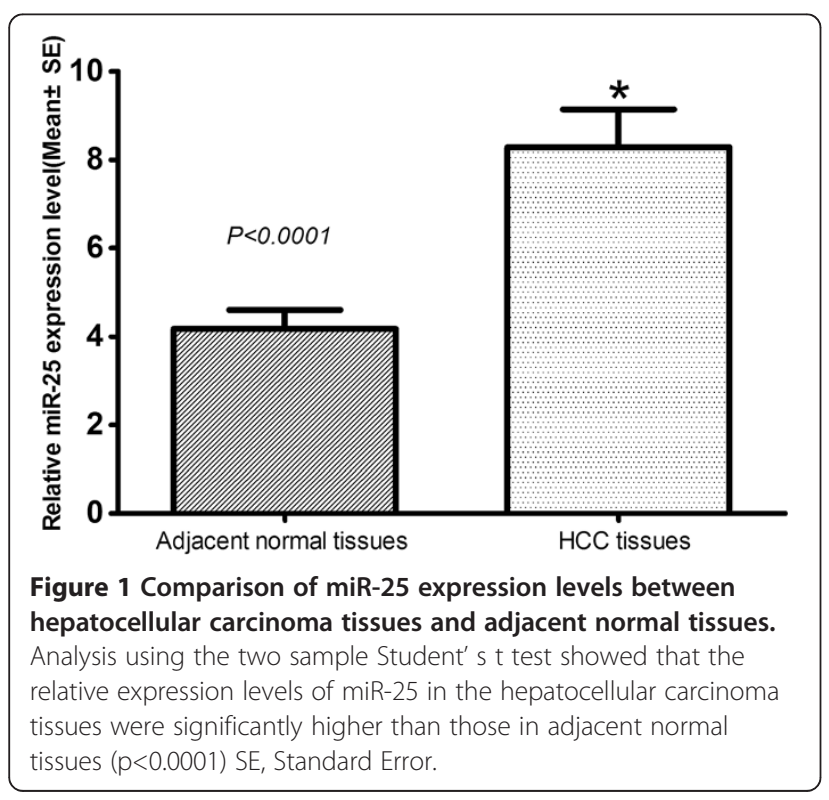

level, we hypothesized that miR-25 might affect the prognosis of HCC patients. To confirm this possibility, the miR-25 expression level and the prognosis of patients with HCC were analyzed by using the Kaplan-Meier method. The results indicated that patients who had high miR-25 expression had a shorter overall survival than patients who had low miR-25 expression (median overall survival, 31 months versus 42.9 months, $\mathrm{p}=0.0192$; Figure 2). The multivariate Cox regression analysis indicated that miR-25 expression $(\mathrm{HR}=2.179 ; \mathrm{p}=0.001)$, TNM stage $(\mathrm{HR}=1.782$; $\mathrm{p}=0.014)$, and vein invasion $(\mathrm{HR}=1.624 ; \mathrm{p}=0.020)$ were independent prognostic factors for overall survival (shown in Table 2).

\section{Discussion}

Although a growing number of novel treatment strategies have been developed for HCC, such as molecular targeted therapy and gene therapy, to our disappointment, satisfactory therapeutic outcomes have not been achieved [21,22]. Considering that the survival rate of HCC is still low, further identification of new prognostic markers remains important for the prevention and treatment of HCC.

The discovery that noncoding components of the genome, including microRNA, can contribute to the pathogenesis of cancer has led investigators to contemplate using these molecules to guide clinical decision making [23]. So far, there are more than 1000 microRNAs annotated by the latest version of miRBase. The expression of miRNAs is remarkably deregulated in HCC, strongly suggesting that miRNAs are involved in the initiation and progression of this disease. MiR-25 is a member of the miR-106b 25 cluster, which includes miR-106b, miR-93 and miR-25, that is located within intron 13 of the minichromosome maintenance protein 7 (MCM7) gene on chromosome 7q22.1 [14].

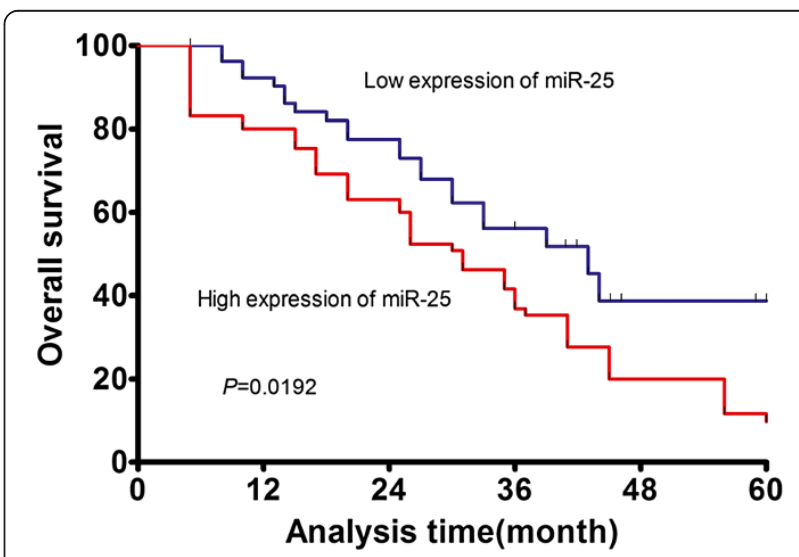

Figure 2 Survival analysis of 131 hepatocellular carcinoma patients by Kaplan-Meier method. Overall survival rate in patients with high miR-25 expression was significantly lower than that in patients with low miR-25 expression ( $p=0.0192$ ). 
Table 2 multivariate analyses of prognostic factors in hepatocellular carcinoma

\begin{tabular}{lllll}
\hline Variable & Subset & \multicolumn{3}{c}{ Overall survival } \\
\cline { 3 - 5 } & & HR & $\mathbf{9 5 \%} \mathbf{C l}$ & $\mathbf{P}$ \\
\hline miR-25 expression & High/low & 2.179 & $1.876-4.335$ & 0.001 \\
Gender & Male/female & 0.982 & $0.901-1.003$ & 0.652 \\
Age at diagnosis & $>50 / \leq 50$ & 1.231 & $0.922-1.523$ & 0.212 \\
Tumor size & $>5 / \leq 5$ & 1.479 & $0.991-2.127$ & 0.090 \\
Tumor number & Multiple/solitary & 1.854 & $0.823-2.132$ & 0.121 \\
TNM stage & III-IV/I-I & 1.782 & $1.389-2.993$ & 0.014 \\
Vein invasion & Presence/absence & 1.624 & $1.233-1.981$ & 0.020 \\
Cirrhosis & Positive/negative & 1.027 & $0.876-1.535$ & 0.320 \\
Hepatitis B virus infection & Positive/negative & 1.002 & $0.892-1.337$ & 0.417 \\
Serum AFP level & $>25 / \leq 25$ & 1.377 & $0.882-1.335$ & 0.398 \\
\hline
\end{tabular}

$\mathrm{Cl}$, confidence interval; $\mathrm{HR}$, hazard ratio; miR-25, microRNA-25.

Previous studies have shown that the expression of miR-25 was up-regulated significantly in human stomach cancer, ovarian cancer, and prostate cancer [16-18]. In the study by Kim BH et al., miR-25 was found to be up-regulated in human gastric carcinoma tissues when compared to adjacent non-neoplastic tissues. The high expression of miR-25 in gastric carcinoma tissues may be a high risk factor associated with tumor penetration through serosa, lymph node metastasis, distant metastasis, and poor long-term survival in patients undergoing radical resection and adjuvant systemic chemotherapy [16]. Poliseno L et al. found that miR106b 25 cluster was aberrantly overexpressed in human prostate cancer, which potentiated cellular transformation both in vitro and in vivo. They demonstrated that the intronic miR-106b 25cluster cooperated with its host gene MCM7 in cellular transformation both in vitro and in vivo [17]. Zhang $\mathrm{H}$ et al. have found that miR-25 was strongly up-regulated in ovarian cancer tissue versus adjacent nontumor tissue. The expression levels of miR-25 in ovarian cancer cell lines were similar with ovarian cancer samples compared with the normal ovarian epithelial cells. Overexpression of miR-25 in ovarian cancer cells enhanced cell proliferation whereas down-regulation of miR-25 induced apoptosis. The effects of miR-25 abrogation were partly mediated by the intrinsic apoptosis pathway. Many proapoptotic proteins such as Bim, Bax and caspase- 3 were up-regulated after transfection [18]. However, investigators also found that expression of miR-25 was down-regulated in other cancer. Li Q et al. found that the expression of miR-25 was down-regulated in colon cancer, and miR-25 might suppress the proliferation and migration of colon cancer cells as a tumor suppressor gene in vitro and in vivo [24]. Therefore, we speculate that the function of miR-25 is tissue specific.

$\mathrm{Li} \mathrm{Y}$ et al. have found that miR-25 was strongly upregulated in HCC tissue when compared with the corresponding paired non-tumor samples. However, the clinical significance of miR-25 gene expression in HCC remains unclear. In the present study, we found that miR-25 expression was proven to be associated with advanced TNM stage, suggesting that miR-25 might be involved in the carcinogenesis and metastasis of HCC. More importantly, we proved that patients with a high expression of miR-25 tended to have shorter survival than patients with lower levels, indicating that high miR-25 level is a marker of poor prognosis for patients with HCC. However, the precise molecular mechanisms behind the altered expression of miR-25 in HCC and its function are not very clear. In the study by Li $\mathrm{Y}$ et al., knock-down studies for the miR-106b-25cluster, which includes miR-106b, miR-93 and miR-25, showed that the expression of the cluster was necessary for cell proliferation and for anchorage independent growth [19]. Additional studies are needed to more clearly and comprehensively articulate the molecular mechanisms of both the cause and the effects of altered expression of miR-25 in the development and/or progression of HCC.

In summary, to the best of our knowledge, the present study is the first to report the differential expression of miR-25 in HCC and the possible use of miR-25 as a novel prognostic marker in HCC. The present findings demonstrate high expression of miR-25 in HCC tissue, which is associated with a poor prognosis in HCC patients. Further studies are needed to elucidate the mechanisms of action of miR-25 in HCC.

\section{Competing interests}

The authors declare that they have no competing interests.

\section{Authors' contributions}

ZXS and JZ carried out the experimental studies and drafted the manuscript. ZHR, WMG, and YGW carried out part of the experimental studies. CKQ designed the experiments and modified the manuscript. All authors read and approved the final manuscript.

\section{Acknowledgement}

This work was supported by Department of science and technology of Shandong Province (No. 2013GSF11862).

\section{Author details}

${ }^{1}$ Department of Hepatobiliary Surgery, ShanDong Provincial Hospital affiliated to ShanDong University, 324 JingWu Road, Jinan, ShanDong Province 250021, China. ${ }^{2}$ Department of Hematology, ShanDong Provincial Hospital affiliated to ShanDong University, Jinan, ShanDong Province 250021, China.

Received: 27 November 2013 Accepted: 10 February 2014 Published: 4 March 2014

\section{References}

1. Jemal A, Bray F, Center MM, Ferlay J, Ward E, Forman D: Global cancer statistics. CA Cancer J Clin 2011, 61(2):69-90.

2. Llovet JM, Burroughs A, Bruix J: Hepatocellular carcinoma. Lancet 2003, 362(9399):1907-1917.

3. Aravalli RN, Steer CJ, Cressman EN: Molecular mechanisms of hepatocellular carcinoma. Hepatology 2008, 48(6):2047-2063.

4. Llovet JM, Bru C, Bruix J: Prognosis of hepatocellular carcinoma: the BCLC staging classification. Semin Liver Dis 1999, 19(3):329-338. 
5. The Cancer of the Liver Italian Program (CLIP) investigators: A new prognostic system for hepatocellular carcinoma: a retrospective study of 435 patients. Hepatology 1998, 28(3):751-755.

6. Ying X, Han SX, Wang JL, Zhou X, Jin GH, Jin L, Wang H, Wu L, Zhang J, Zhu Q: Serum peptidome patterns of hepatocellular carcinoma based on magnetic bead separation and mass spectrometry analysis. Diagn Pathol 2013, 8(1):130.

7. Guo X, Xiong L, Sun T, Peng R, Zou L, Zhu H, Zhang J, Li H, Zhao J: Expression features of SOX9 associate with tumor progression and poor prognosis of hepatocellular carcinoma. Diagn Pathol 2012, 7:44.

8. Guo X, Xiong L, Zou L, Sun T, Zhang J, Li H, Peng R, Zhao J: L1 cell adhesion molecule overexpression in hepatocellular carcinoma associates with advanced tumor progression and poor patient survival. Diagn Pathol 2012, 7:96.

9. Schmilovitz-Weiss H, Tobar A, Halpern M, Levy I, Shabtai E, Ben-Ari Z: Tissue expression of squamous cellular carcinoma antigen and Ki67 in hepatocellular carcinoma-correlation with prognosis: a historical prospective study. Diagn Pathol 2011, 6:121

10. Ambros V: The functions of animal microRNAs. Nature 2004, 431(7006):350-355.

11. Zhang R, Su B: Small but influential: the role of microRNAs on gene regulatory network and 3'UTR evolution. J Genet Genomics 2009, 36(1):1-6.

12. Erson AE, Petty EM: MicroRNAs in development and disease. Clin Genet 2008, 74(4):296-306

13. Liu W, Mao SY, Zhu WY: Impact of tiny miRNAs on cancers. World J Gastroenterol 2007, 13(4):497-502.

14. Petrocca F, Vecchione A, Croce CM: Emerging role of miR-106b-25/miR-17-92 clusters in the control of transforming growth factor beta signaling. Cancer Res 2008, 68(20):8191-8194.

15. Savita U, Karunagaran D: MicroRNA-106b-25 cluster targets beta-TRCP2, increases the expression of snail and enhances cell migration and invasion in H1299 (non small cell lung cancer) cells. Biochem Biophys Res Commun 2013, 434(4):841-847.

16. Kim YK, Yu J, Han TS, Park SY, Namkoong B, Kim DH, Hur K, Yoo MW, Lee HJ, Yang HK, Kim VN: Functional links between clustered microRNAs: suppression of cell-cycle inhibitors by microRNA clusters in gastric cancer. Nucleic Acids Res 2009, 37(5):1672-1681.

17. Poliseno L, Salmena L, Riccardi L, Fornari A, Song MS, Hobbs RM, Sportoletti P, Varmeh S, Egia A, Fedele G, Rameh L, Loda M, Pandolfi PP: Identification of the miR-106b 25 microRNA cluster as a proto-oncogenic PTEN-targeting intron that cooperates with its host gene MCM7 in transformation. Sci Signal 2010, 3(117):ra29.

18. Zhang H, Zuo Z, Lu X, Wang L, Wang H, Zhu Z: MiR-25 regulates apoptosis by targeting Bim in human ovarian cancer. Oncol Rep 2012, 27(2):594-598.

19. Li Y, Tan W, Neo TW, Aung MO, Wasser S, Lim SG, Tan TM: Role of the miR-106b-25 microRNA cluster in hepatocellular carcinoma. Cancer Sci 2009, 100(7):1234-1242.

20. Varotti G, Ramacciato G, Ercolani G, Grazi GL, Vetrone G, Cescon M, Del Gaudio M, Ravaioli M, Ziparo V, Lauro A, Pinna A: Comparison between the fifth and sixth editions of the AJCC/UICC TNM staging systems for hepatocellular carcinoma: multicentric study on 393 cirrhotic resected patients. Eur J Surg Oncol 2005, 31(7):760-767.

21. Qu L, Wang Y, Gong L, Zhu J, Gong R, Si J: Suicide gene therapy for hepatocellular carcinoma cells by survivin promoter-driven expression of the herpes simplex virus thymidine kinase gene. Oncol Rep 2013, 29(4):1435-1440

22. el Tazi M, Essadi I, M'Rabti H, Touyar A, Errihani PH: Systemic treatment and targeted therapy in patients with advanced hepatocellular carcinoma. North Am j Med Sci 2011, 3(4):167-175.

23. Nana-Sinkam SP, Croce CM: Clinical applications for microRNAs in cancer. Clin Pharmacol Ther 2013, 93(1):98-104.

24. Li Q, Zou C, Zou C, Han Z, Xiao H, Wei H, Wang W, Zhang L, Zhang X, Tang Q, Zhang C, Tao J, Wang X, Gao X: MicroRNA-25 functions as a potential tumor suppressor in colon cancer by targeting Smad7. Cancer Lett 2013, 335(1):168-174.

doi:10.1186/1746-1596-9-47

Cite this article as: Su et al:: Upregulation of microRNA-25 associates with prognosis in hepatocellular carcinoma. Diagnostic Pathology 2014 9:47.

\section{Submit your next manuscript to BioMed Central and take full advantage of:}

- Convenient online submission

- Thorough peer review

- No space constraints or color figure charges

- Immediate publication on acceptance

- Inclusion in PubMed, CAS, Scopus and Google Scholar

- Research which is freely available for redistribution 